\title{
Satın Almalar ile Gerçekleşen Değişim Sürecinde Çalışan Duygularının Yönetimi: Bir Restoran Örneği*
}

\author{
Prof. Dr. Meryem AKOĞLAN KOZAK \\ Anadolu Üniversitesi, İşletme Fakültesi, Konaklama İşletmeciliği Bölümü, Eskişehir, \\ e-posta: mkozak@anadolu.edu.tr
}

\author{
Arş. Gör. Volkan GENÇ \\ Batman Üniversitesi, Turizm İşletmeciliği ve Otelcilik Yüksekokulu, Batman, e-posta: \\ volkangnc@yahoo.com
}

Öz

Bu çalışmada, bir restoran işletmesinin başka bir işletme tarafından satın alınması sürecinde yaşanan çalışan direncinin önlenmesinde, duyguların yönetimine dikkat çekilmektir. Restoran işletmelerinin insan odaklı yapısı dikkate alındığında direnci önlemede, geleneksel yöntemler yanında, duyguların yönetiminin kullanılabilir bir teknik olarak önerilmesi araştırmanın temel amacıdır. Araştırmada, verilerin toplanmasında derinlemesine görüşme tekniğinden yararlanılmıştır. Görüşmeler, Çanakkale il merkezinde yeni satın alımı gerçekleşmiş bir restoran işletmesinde görev yapan 5 çalışan ile gerçekleştirilmiştir. Çalışanlara konu ile ilgili üç temel soru sorulmuş, sorular ses kayıt cihazı ile kayıt altına, alınmış, sonrasında deşifre edilmiştir. Manuel olarak yapılan değerlendirmelerde, üç ana tema olarak belirlenen sorulara verilen cevaplar incelenmiştir. Sonuçta, çalışanların değişim sırasında karmaşık (olumlu ve olumsuz birlikte) duygular yaşadıkları; pasif direnç gösterdikleri, yöneticilerin çalışanlara empati göstermediği ve direnç sürecinde sosyal ilişkilerin önemli bir bağlayıcı unsur olduğu görülmüştür. Bu süreçte yöneticilerin değişime direnç gösterimlerde onların duygusal ve sosyal ilişkilerini anlamaları ve öncelikle bu ilişkileri yönetmeleri gerekmektedir.

Anahtar Kelimeler: Değişime direnç, İşletmenin satın alınması, Duyguların yönetimi, Restoran işletmesi

*Bu çalışma 18. Ulusal Turizm Kongresinde bildiri olarak sunulmuştur.

\section{Önerilen Atıf:}

Akoğlan Kozak, M. ve Genç, V. (2018). Satın Almalar ile Gerçekleşen Değişim Sürecinde Çalışan

Duygularının Yönetimi: Bir Restoran Örneği, Türk Turizm Araştırmaları Dergisi, Cilt.2, Sayı.1, ss.27-43. 


\title{
Management of the Emotions of Employees in the Process of Change Acquisition: A Restaurant Example
}

\author{
Prof. Dr. Meryem AKOGLAN KOZAK \\ Anadolu University, Faculty of Business Administration, Hospitality Management \\ Department, Eskisehir, e-mail: mkozak@anadolu.edu.tr
}

\section{Research Assistant Volkan GENC \\ Batman University, Tourism and Hotel Management School, Batman, e-mail: volkangnc@yahoo.com}

\begin{abstract}
In this study, it is aimed to draw attention to the management of the emotions of a restaurant employee in the process of being bought by another business and avoiding the experienced resistance. Given the human-oriented nature of restaurant businesses, it is suggested that using the management of feelings as a usable technique along with traditional methods are the main objectives of research in the prevention of resistance. In the study, in-depth interviewing techniques were used to collect data. The interviews were carried out with 5 employees working in a restaurant where a new purchase was just carried out in Çanakkale province center. The employees were asked three basic questions about the subject. The questions were recorded via voice recorder, taken, and then deciphered. In manual assessments, the answers to the three main themes were examined. As a result, it was found out that employees had complicated (positive and negative) feelings during the change and displayed passive resistance while managers did not show empathy to employees, and social relations were an important binding factor in the resistance process. Keywords: Resistance to change, Acquisition of establishments, The Management of Emotion, Restaurant establishments
\end{abstract}

\section{Suggested Citation:}

Akoğlan Kozak, M. ve Genç, V. (2018). Management of the Emotions of Employees in the Process of Change Acquisition: A Restaurant Example, Journal of Turkish Tourism Research, Vol.2, Issue.1, pp.27-43. 


\section{Gíriş}

Günümüzde yaşanan Rusya ile uçak krizi, Suriye'deki savaş, Türkiye'de yaşanan terör saldırıları, Avrupa Birliği'ne giriş kimi sorunlar, işletmeleri yeni gelişmelerle karşı karşıya bırakarak, hızlı çözüm üretmeye zorlamaktadır. Bu süreçte yaşanan bu değişimlerle baş etmek için işletmelerin bazı stratejileri uygulamaları gerekmektedir. Birleşme, stratejik ortaklık, toplam kalite, küçülme, ortak girişim, kıyaslama ve satın alma, değişim sürecinde en sık uygulanan stratejiler olarak sayılabilir. Satın alma, başka bir ifadeyle, yeni bir işletme alma en kısa şekliyle; işletmenin bir başka işletme tarafından satın alınması ya da işletmenin bir başka işletme alması durumudur. Satın alma dönemi, önemli değişimleri de beraberinde getirdiğinden işletmelerin $\% 50$ 'si ile \%80'inin bu nedenle başarısız olduğu (Gunkel vd., 2015; Sinkovics vd., 2011; Kusstatscher ve Cooper, 2005) dikkat çekmektedir. Burada, işletme sahip ve yöneticilerinin genellikle kararın finansman ve ekonomik yönüne ağırlık verdikleri, olayın insani boyutunu göz ardı ettikleri etkili olmaktadır. Aslında, değişimin sonuçları maddi yönden olduğu kadar, maddi olmayan yönleriyle de işletmeyi etkilemektedir. Çalışanlar bu bağlamda, değişim sürecinin önemli aktörleri olarak, değişimin sonuçlarından en fazla etkilenen boyutu oluşturmaktadırlar. Dolayısıyla, insani boyuttaki sorunların üstesinden gelmeden, çalışanları değişime hazırlamadan ve kabulünü sağlamadan yapılan satın almanın başarısız olacağı ileri sürülebilir (Vos, 2006; Barutçugil, 2004).

İnsan yönetme ve manipüle etmede, fiziksel ve zihinsel kimi tatmin araçlarını yerini bugünlerde duygular almıştır. Çalışanların duyguları bu tür değişiklerin kabulünde ve değişim yönetiminde son derece önemli hale gelmiştir. Özellikle kirli bilgi, rekabet, kültürel etkileşimler, işi kaybetme, yeni duruma adapte olamama vb. korkular çalışanlarda bazı olumsuz duyguların ortaya çıkmasına neden olmaktadır (Kusstatscer ve Cooper, 2005).

Araştırmalar, gerek müşteri tatmini ile ilgili yenilikler gerekse bu yeniliklerin uygulanmasına bağlı yapılan değişimlerde çalışanların duygularının pek fazla önemsenmediğini göstermektedir (Coch ve French, 1948; Akoğlan Kozak, 2004; Sabuncuoğlu ve Tüz 2005; Vos, 2006, Burnes ve Jackson, 2011; Klarner vd., 2011). Bu bağlamda duygular, insan davranışının önemli bir parçası olup iş hayatındaki rolleri ve davranışları etkilemektedir (Erkuş ve Günlü 2008). Duygular; yaşama yönelik bakış açısını, morali ve performansı olumlu veya olumsuz yönde etkileyebildiğinden, 
çalışanlar için önemlidir ve iyi yönetilebilirse bireylerin morali ve performansı üzerinde olumlu etkileri olmaktadır (Akoğlan Kozak ve Genç, 2014; Barutçugil, 2004; Oreg, 2006; Kusstatscher ve Cooper, 2005). Ancak bu çalışmalarda duyguların nasıl yönetileceği konusunun ihmal edildiği dikkat çekmektedir (Kusstatscher ve Cooper, 2005).

Türkiye'de 2016 yılında ev dışında yemek yeme harcamaları 44 milyar TL olarak gerçekleşmiştir. Restoran işletmeleri bu harcamalarda \%20'lik payına sahiptir. Aynı zamanda 2016 yılı bir önceki yıla göre 11 milyar TL gerilemiştirir. Yeme içme sektöründe önemli bir yoğunluk alanı olan restoranlar ise küçük ölçekli işletme yapıları nedeniyle, bu tür değişimden kaynaklanan sorunlara sık sık maruz kalan işletme grubunu teşkil etmektedir. Örneğin, 2010 yılından itibaren önemli şirketlerin restoranlar satın aldığı ve buna bağlı değişimler yaşadıkları görülmektedir (İşbankası Num Num restoran zinciri, Doğuş Grup, BVS Grup vb.) $)^{2}$ Bu nedenle planlanan bu çalışma, konu ile ilgili dikkat çekici literatür boşluklarına katkısı yanında, uygulamacılara kolaylaştırıcı bazı öneriler sunması bakımından da önemlidir. Çalışmada, bir restoranın satın alınması sürecinde yaşanan sorunların, duygu yönetimi ile bertaraf edilebileceği konusu bir örnek olay üzerinden ele alınacaktır.

\section{İşletmelerin Satın Alınması Sürecinde Direnç ve Duyguların Yönetimi}

Çalışanların değiş̧imlere gösterdikleri tepkiler, aslında yaşadıkları duyguların bir yansımasıdır. Duygular genellikle direnç gösterme, değişime engel olma, güvensizlik, şüphe ya da değişimi önleme gibi çalışan davranışları ile kendini göstermektedir (Liu ve Perrewe, 2005). Duygu gösterimlerinde ise değişimin niteliği ya da derinliği belirleyici olabilmektedir. Örneğin, satın almalar önemli değişimleri getirirken, büyüme ya da kıyaslama sonucunda çalışanların fazla etkilenmeleri söz konusu olmayabilmektedir. En bilindik şekliyle satın alma; bir işletmenin tamamı veya çoğunluk hisselerini satın alarak o işletmenin kontrol altında kendine bağlı bir işletme haline getirilmesidir. Satın alma sonucunda işletmelerin tüzel kişiliği sona ermemekte, ancak işletmenin çoğunluk hisseleri ve yönetimi satın alan işletmenin kontrolü altına geçmektedir (Ülgen ve Mirze, 2010). Bu süreçte, işletmede önemli değişimler meydana gelmekte ve çalışanlar bu süreçte işten çıkarılma korkusu,

\footnotetext{
${ }^{1}$ http://www.hurriyet.com.tr/avrupalilar-ev-disinda-turkiyeden-8-katfazla-tuketiyor-40469515

${ }^{2}$ http://www.haberturk.com/ekonomi/para/haber/831145-turkmutfaginin-yeniden-dogusu
} 
pozisyonda değişim yaşanacağı hissi, güç ve statü kaybı endişesi gibi nedenlerle olumsuz etkilenmektedirler.

Scott ve Jaffe (1988) değişimi dört aşamalı olarak açıklamışlardır. Bu aşamalar sırasıyla; inkar, direnç, kademeli keşif ve bağlılıktır. İlk iki aşama çalışan tarafından bilinen ya da bilinmeyen ancak beklenen olaylardan dolayı doğal veya doğal olmayan tepkilerdir. Bu aşamaları kırmak kolay değildir. Değişime adapte olmak bilişsel ve duygusal olarak gösterdikleri bir süreçtir. Bu süreci Marks ve Mirvis (1988) “birleşme sendromu" olarak tanımlamaktadırlar. Bir bakıma çalışanların değişim sürecinde karar vermenin merkezileşmesi, güç oyunları, stres, güvensizlik, kaygı gibi nedenlerle gösterdikleri reaksiyonları ifade etmektedir. Satın alma süreci ve sonrasında satın alınan işletme tarafından üst kademelere yeni yöneticiler alınması oldukça yaygın bir uygulamadır. Bu durumda eski sistemde belirli güç ve etkisi olan kişilerin sahip olduğu güç ve etkileme yeteneğini kaybedecekleri düşüncesiyle direnişe geçebilmekte ve/ya işletme içerisindeki informal yapıyı harekete geçirebilmektedir (Akoğlan Kozak, 2004). Duygular ise değişim sürecinde ve belirsizlik durumunda çalışma düzeninde oluşan olayların yorumlanmasını yansıtır (Klarner vd., 2011). Önceki çalışmalar örgütsel değişime olan olumsuz tepkilerin ve değişim girişimlerinin başarı ya da başarısızlığını anlamada duyguların önemini vurgulamaktadır (Fugate vd., 2002; Mossholder vd., 2000). Bu nedenle, devam etmekte olan değişim dinamiklerini anlamada önemli bir husus değişimin olumsuz duygularla olan ilişkisidir. Örneğin, Sinkovics vd., (2011) birleşme ve satın alma sürecinde çalışanların olumsuz duygular yaşadıkların ortaya koymuşlardır.

Direncin önlenebilmesinde yöneticilere önemli roller düşmektedir. Gunkel vd., (2015) tarafından yapılan bir çalışmada, birleşme ve satın alma sürecindeki yönetsel desteğin çalışanların duygularını ve aktif direniş davranışlarını olumlu yönde etkilediğini ortaya koymaktadır. Araştırmacılar bu durumun çalışanların işgören devir hızını da etkilediğini tespit etmişlerdir. Başka bir çalışmada ise Pardo del Val ve Fuentes (2003) çalışanların değişime direnç göstermesinde köklü değerlerin varlığına işaret etmektedir. Dolayısıyla, yöneticilerin bu süreçte çalışanları anlamadığında ya da anlamak istemediğinde ileriki zamanlarda telafisi zor olan sonuçlara neden olabilmektedir. Kötü yönetilen değişim, çalışanlar arasında değişimin olumsuz yönlerinin abartılarak direnç gösterimleriyle sonuçlanabilmektedir (DiFonzo vd., 1994). Değişim sürecinde çalışanların yaşayacağı duygular bastırılmamalı, ortaya çıkan duyguların nedenleri iyi analiz edilmelidir. Bu dönemde çalışanların korkularının farkında olunmalı, değişime karşı olan algıları yönetilmelidir. Elving (2005) yapmış olduğu çalışmada çalışanların değişime direnç göstermesinin temel 
nedenlerinden biri olarak iş güvensizliği ve belirsizliğin olduğunu, çalışanların bu algılarının yönetilmesi gerektiğini belirtmiş̧tir. Folger ve Skarlicki (1999) çalışmalarında çalışanların değişime direnç göstermelerinin çalışanlar arasında adaletsizlik algısının yer aldığını ve bunun sonucunda da çalışanların değişime karşı korku yaşadıklarını ifade etmişlerdir. Coghlan (1993) çalışmasında çalışanların değişime karşı direnç göstermesinde yaşadıkları korkuların etkili olduğunu ifade etmektedir.

Yöneticilerin direnci daha iyi anlaması ve yönetebilmesinde empati yetkinliğinin ve örgüt içerisindeki sosyal ilişkilerin anlaşılması dikkate değerdir. Literatür de bunu destekler niteliktedir. Vakola vd., (2004)'nin yapmış oldukları araştırmada empati kurabilen yöneticilerin değişimi daha kolay kabul ettirdikleri ortaya çıkmıştır. Huy (1998) da değişimlerde yöneticinin empati kurmasının sürecin yönetilmesinde önemli bir yetkinlik olduğunu belirtmiş̧ir. Oreg (2006) çalışanların değişime direnç gösterimleri ile sosyal ilişkilerin bağlantılı olduğunu tespit etmiştir.

Değişimde direnç gösterim nedenlerinden bir diğeri de çalışanın yaşadığı duygusal karmaşadır. Duygusal karmaşa, çalışanın örgüt içerisinde hem olumlu hem de olumsuz duyguyu aynı anda yaşamasıdır (Akoğlan Kozak ve Genç, 2004). Piderit (2000) tarafından yapılan bir araştırmada, duygusal karmaşanın örgüt içerisinde olumlu ve olumsuz etkilerinin olacağına değinilmiş ve değişim yöneticileri örgüt içerisinde çalışan duygularını yönetebilirlerse değişimin başarıyla sonuçlanabileceği belirtilmiş̧ir. Duygusal karmaşa yaşayan çalışanın direncini kırmanın tamamen olumsuz duygular içerisinde olan çalışana göre daha kolay olduğu söylenebilir. Burada önemli olan çalışana değişim sonrasında olumsuzluk yaşamayacağ yaratabilmektir. Çalışan duygularının yönetilememesi sonucunda değişimlerin başarılı olamadığını ve mevcut direnç önleme yöntemleriyle istenen başarıların elde edilemediği ve eksikliklerinin devam ettiği güncel çalışmalarla tespit edilmiştir (Avey vd., 2008; Klarner vd., 2011).

Değişim olgusu işletme içerisinde hissedildiği andan itibaren çalışanlar arasında bazı duygular yayılmaktadır. Literatürde bu duygusal bulaşma ve duygu iklimi olarak adlandırılmaktadır. Duygu iklimi, "çalışanların ya da müşterilerin bir işletmede fiziksel yerine duygusal olarak hissettikleri deneyimler" olarak tanımlanmaktadır (Schein, 1999: 3). Duygusal bulaşma ile birlikte işletme içerisindeki iklim olumlu ya da olumsuz şekilde değişebilmektedir. Kiefer (2002) yapmış olduğu nicel araştırmada devam eden değişimlerin çalışanların olumsuz duygularıyla ilişkili olduğunu ve bunun sonucunda çalışanların geri çekilme ve güven problemi yaşadıklarını ortaya koymaktadır. Avey vd., (2008) değişim sürecindeki pozitif duyguların psikolojik 
sermaye ile ilişkili olduğunu ortaya koymaktadır. Bovey ve Hede (2001) yaptıkları çalışmada çalışanların duygusal fikirlerinin değişime direnç davranışlarını etkilediğini tespit etmişlerdir.

Örgütlerde direnç gösterim sonucunda çalışanların davranışlarını etkileyen bazı sonuçlar yaşanmaktadır. Oreg (2006) tarafından yapılan çalışmada duygusal direncin iş tatmini olumsuz olarak davranışsal direncin de işten ayrılma niyetini etkilediği tespit edilmiştir. Vakola vd., (2004) tarafından yapılan başka bir çalışmada örgütsel değişimlerin işgören devir hızını arttırdığı ve iş tatminini düşürdüğü tespit edilmiştir. Dolayısıyla, değişimin başarısında hem bireysel hem de örgütsel sadakatin yaratılması ve çalışanların değişime karşı tutumlarının olumlu yönde değiştirilmesi önemlidir.

\section{YÖNTEM}

Restoran işletmelerinde son yıllarda yaşanan devretme ve satın almalardaki (www.ey.com) değişim sorunlarının önlenmesi bu çalışmanın temel sorunu olarak belirlenmiştir. Satın alma süreci ve sonrasında çalışanların hayatını etkileyecek kararlarda çalışanların ne hissettiklerini tam olarak anlayamadan ve doğru yönetemeden bu sürecin başarılı olması mümkün görülmemektedir. Bu nedenle, satın almalar sürecinde duyguların önemsenmesi gerekmektedir. Duyguların yönetimi direnci ve insan ilişkilerini anlama bağlamında da önemlidir. Ancak satın almalarla ilgili çalışmaların daha çok ekonomi ve finans konularında olması, insan faktörünün ve duyguların ihmal edildiğine işaret etmektedir (Gunkel vd., 2015; Fugate vd., 2002). $\mathrm{Bu}$ araştırmada ise satın alma sürecinde ortaya çıkan dirençle baş etmek ve direnci önlemek için duyguların yönetimi önerilmektedir. Veriler, yüz yüze yapılan derinlemesine görüşmelerle toplanmıştır. Araştırma Çanakkale'deki bir restoranda yapılmıştır. Araştırma alanı, Çanakkale'nin son yıllarda iç turizmde yakaladı̆̆ı ivme ile ilgili olduğu kadar, satın alımı yeni gerçekleşen bir restoran olması ve araştırma için izin verilmesi nedeniyle seçilmiştir. Görüşmeler toplam 5 çalışan ile yürütülmüştür. Görüşmelerde çalışanlara şu açık uçlu sorular sorulmuştur;

- Restoranın satın alındığını öğrendiğinizdeki duygularınızı anlatır mısınız? Neler hissettiniz?

- Restoran satın alındığında yönetici ve amirlerinizin size hangi duygularla yaklaşmasını, nasıl davranmasını isterdiniz? 
- Restoran satın alındıktan sonra işletme içerisinde neler yaşandı? Siz bu durumlarda hangi duyguları yaşadınız ve buna nasıl tepki verdiniz?

Görüşme talebini kabul eden çalışanlardan telefon ile randevu alınmıştır. Görüşme talebi 10 Aralık 2015 tarihinde iletilmiş ve katılımcının ve araştırmacının müsaitliği doğrultusunda ilk görüşmeler 19 Aralık 2015 tarihinde gerçekleştirilmiştir. Daha sonra 26 Aralık 2015-02 Ocak 2016 tarihleri arasında kalan 2 kişi ile görüşme yapılmıştır. Görüşmeler katılımcıların uygun gördükleri saatlerde çalıştıkları restoran işletmesinde ve iş dışında bir kafede gerçekleştirilmiştir. Görüşme esnasında ses kayıt cihazı bulundurulmuştur. Görüşmeler esnasında katılımcılara yöneltilen sorulara verilecek yanıtların sadece araştırma amacıyla kullanılacağı ve bu bulgular yorumlanırken herhangi bir şekilde isim/soy isim/ işletme adının kullanılmayacağı ifade edilerek görüşmenin gerçekleşmesi amaçlanmıştır.

Toplana ses kayıtları deşifre edildikten sonra üç defa okunmuştur. Elde edilen 17 sayfalık deşifre metinleri manuel olarak içerik analizine tabii tutulmuştur. İçerik analizinde görüşmede kullanılan 3 soru araştırmanın ana teması olarak alınmış ve görüşme içerikleri bu bağlamda analiz edilmiştir. Ana tema oluşturulurken bu konuda çalışma yapan farklı üç araştırmacıya, konu ayrı ayrı kontrol ettirilmiştir.

Araştırma kapsamında 5 kişi ile görüşülmüşsür. Bu kişilerin; yaşları, 22 ile 36 arasında değişmekte, biri kadın, diğerleri erkek olup, üçü garson, diğerleri ise aşçı olarak çalışmakta, çalışma süreleri ise 4 ile 10 yıl arasında değişmektedir. Satın almanın gerçekleştiği otel restoranı ise 23 yıldır faal olup, otel ve otel dışı müşterilere alakart servis olarak hizmet vermektedir.

\section{DEĞERLENDİRME}

Bir restoran işletmesinin satın alınmasıyla birlikte çalışanların duygusal anlamda yaşadıkları sorulanlara cevap aramak amacıyla yürütülen görüşmeler sonucunda elde edilen bulgular üç başlık altında toplanmıştır.

\section{- Restoranın satın alma sürecindeki çalışan duyguları}

Değişim sürecinde çalışanların yaşadıkları duygular işletme performansını doğrudan ya da dolaylı etkilediği için araştırmacılar (Marks ve Mirvis, 1988; Cartwright ve Cooper, 1990; Kusstatscher ve Cooper, 2005) tarafından üzerinde durulan bir konu olmuştur. Çalışanların bu süreçte hangi duyguları yaşadıklarını ortaya koymak ve bu 
duyguların bir direnç gösterimine neden olup olmadığını ortaya koymak amacıyla "Restoranın satın alındı̆̆ın öğrendiğinizde duygularınızı anlatır mısınız? Neler hissettiniz?" sorusu katılımcılara sorulmuştur. Katılımcılar bu süreçte en çok durumun belirsizliği, işten çıkarılma gibi nedenlerle korku, stres, üzüntü yaşadıklarını belirtmektedirler (4 çalışan). Bir çalışanın bu konuda öne çıkan ifadesi şu şekildedir:

...yöneticilerimiz işletmenin başkası tarafından satın alınacağını söylediklerinde korkuya kapılmıyoruz dersek yalan olur. Çünkü satın alma yaşandığında bize ne olacak, işten çıkarılacak mıyız? Yoksa yeni bir müdür mü gelecek başımıza? Bu müdür bize nasıl davranacak? Her zaman alı̧kın olduğumuz sistem aynen devam edecek mi? soruları aklımıza gelmekte ve bu durum da bizde korkuya neden olmaktadır (Erkek, çalışan, 7 yıllık i̧̧ deneyimi, restoran işletmesi).

Açıklamalar çalışanların olumsuz duyguları değişim sürecinde sık yaşadıklarını ortaya koymaktadır. Özellikle, bu süreç çalışanların duygusal durumlarını ve ruh hallerini etkilemektedir. Çalışanların ifade ettiği bu duygu çalışanların direnç gösterim nedenlerini ve bu duygunun yönetilmesi gerektiğini de açıklamaktadır.

Korku dışında zıt duyguların da yaşandığı görülmektedir (2 çalışan). Literatürde bu durum duygu karmaşası olarak ifade edilmektedir. Duygu karmaşası, bir çalışanın bir olay karşısında aynı anda iki zıt duyguyu hissetmesidir. Bir çalışanın bu konuda öne çıkan ifadesi şu şekildedir:

...biz burada dışarıda da çok yakın olduğumuz kişilerle çalışıyoruz. Birbirimizle iletişimimiz çok iyi.

...ancak satın alma gerçekleştiğinde başka kişilerden duyuyoruz ki bazı çalışanlar işten çıkarılacak. Bizler de hem yeni bir işletmenin satın almasından dolayı mutluluk yaşarken aynı zamanda başımıza ne gelecek korkusu da yaşıyoruz. (Erkek, çalışan, 4 yıllık iş deneyimi, restoran işletmesi).

Farklı duyguları bir arada yaşamak insanoğlunun doğasında vardır. Merak ve bilinmeyen ikilemi arasında insan farklı arayışlar içerisine girebilmektedir. Geleceğin daha iyi olacağına inanmak ya da gelecekten korkmak sürecin unsurları arasındadır. Yukarıda da ifade edilen çalışanların yaşadığı bu duygusal durum dolayısıyla değişime karşı bir direnç nedeni olabilmektedir ve çalışanların yaşadığı farklı duyguların yönetilmesine ihtiyaç duyulmaktadır.

Değişimler çalışanlar üzerinde sadece olumsuz ve karmaşık duyguları barındırmadığını bunun yanında, ortaya çıan sinerjinin olumlu etkilerinin de 
olabileceği bazı araştırmalarla tespit edilmiştir (Kusstatscher ve Cooper, 2005). Görüşmelerde bir katılımcı bu bağlamda duygularını şöyle ifade etmiştir:

...birkaç aydır maaşımızı düzenli alamıyorduk. X işletmesi satın aldıktan sonra yeni patron bundan sonra maaşlarımızı düzenli alacağımızı ve işletmenin baştan sona tadilattan geçeceğini söyledi. Hepimiz de bu mutluluk yaratt. Çünkü restorandaki malzemeler çok eskiydi ve sürekli müşteri şikâyetleri oluyordu (Kadın, çalışan, 6 yıllık iş deneyimi, restoran işletmesi).

Direnci önlemenin bir diğer yolu işletmede çalışan duygularını ve örgüt iklimini olumluya çevirebilmektir. Bu restoran işletmesinde çalışan duyguları ne kadar olumluysa bu durum çalışan performansına ve müşteri memnuniyetine yansıyacaktır. Dolayısıyla, satın salma süreci ve sonrasında çalışanların duygularının olumlu olması direncin yayılmasını azaltması ve iyi örgüt iklimi bakımından önemlidir. Görüşülen beş katılımcının da değişimi kabul etmenin onların performansında ve huzurunda bir olumsuzluğa sebep olmadığını söylemesi, değişimin olumlu karşılandığı ve fazla direnç olmadığına işaret etmektedir.

- Restoranın satın alma sürecinde çalışanların yönetici davranışları ile ilgili duyguları

Değişime karşı gösterilen direnç, satın alma süreci ve sonrasında yaşanabilecek olası bir durumdur (Marks ve Mirvis, 2011). Yöneticilerin işletme içerisinde var olan direncin önlenmesinde çalışan duygularını anlaması ve yönetebilmesi oldukça önemlidir. Buna bağlı olarak katılımcılara "Restoran satın alındığında yönetici ve amirlerinizin size hangi duygularla yaklaşmasını, nasıl davranmasını isterdiniz?" sorusu yöneltilmiştir. Çalışanlar özellikle yöneticilerin duyguların farkında olması bağlamında empati kavramını ifade etmişlerdir (3 çalışan). Empati, bireyin kendisini karşısındakinin yerine koyarak, onun duygu, düşünce ve davranışlarını anlama süreci olarak ifade edilmektedir. Çalışanlar değişim sırasında yöneticilerin ve patronların kendilerini anlamalarını beklemektedir. Değişimin onlar için kolay olmadığının ve yaşadıkları duyguların farkında olunmasını istemektedirler. Yöneticiler onları anlamadıklarında çalışanlar duygusal bir çöküntü yaşamakta, aktif olmasa bile direnç göstermekte ve bu durum onların performanslarını etkilemektedir. Bir çalışanın bu konuda öne çıkan ifadesi şu şekildedir:

...burada kemik bir kadro vardı. Birbirlerini seven, tanıyan insanlardı. Satın alma sonrasında bazı arkadaşlarımız işten çıkartıldı. Biz baya bir kendimize gelemedik. İsterdik ki yöneticilerin bu insanlara bir şans verip işten çıkmamaları konusunda yardımol olmalarıyd. Ancak böyle olmadı (Kadın, çalışan, 6 yıllık iş deneyimi, restoran işletmesi). 
Başka bir çalışan ise duygularını şöyle dile getirmiştir:

...bizler genellikle ekip olarak birlikteyiz ve bir arkadaşımız çıkarılmak istediğinde buna karşı çıkıyoruz. Satın alma sonrasında şefimiz işten çıkarıldı ve biz buna karşı tepki gösterdik (Erkek, çalışan, 10 yıllık iş deneyimi, restoran işletmesi).

Çalışanların ifadeleri, değişim sürecindeki yüksek duygu durumuna, empati de sosyal ilişkileri yönetmek olgularına dikkat çekmektedir (Boyatzis, 2009). Çalışanlar kendilerini ifade edemediği veya yöneticilerin çalışanların bu süreçte neler hissettiklerini anlamadıklarında ve onlarla empati kuramadıklarında direnç kaçınılmaz olarak ortaya çıkmaktadır. Bu restoranda bu sürecin yöneticiler tarafından daha yönetilmesine ihtiyaç olduğunu, görüşülen beş kişiden üçünün yöneticiler tarafından bu süreçte çalışanlara yönelik empati kurulmadığında olumsuz duygulara (kızgınlık, öfke vb.) yol açtığına işaret etmektedir.

- Restoran satın alma sonrasında ortaya çıkan çalışan duyguları

Çalışanlar satın alma sonrasında hissettikleri, gördükleri ve yaşadıkları olaylara bağlı olarak duygusal ve davranışsal tepkiler göstermektedir. Duygusal ve davranışsal tepkiler aslında bir direnç göstergesidir ve yöneticilerin bu duruma müdahale etmelerini gerektirmektedir (Sinkovics vd., 2011). Çalışanların satın alma sonrasındaki tepkilerinin öğrenilmesi amacıyla "Restoran satın alındıktan sonra işletme içerisinde neler yaşandı? Siz bu durumda hangi duygular yaşadınız ve buna nasıl tepki verdiniz?" sorusu yöneltilmiştir.

Satın alma sonrası çalışanların gösterdikleri direncin ortaya çıkmasında, sosyal ilişkiler son derece önemlidir (Kusstatscher ve Cooper, 2005). Burada da çalışanlar direnç gösteriminde sosyal ilişkilerin rolüne işaret etmişlerdir (3 çalışan). Sosyal ilişkiler çalışanların iş dışında veya mola zamanlarında beraber vakit geçirdiği, konuşmaktan hoşlandığı, sırrını paylaştığı, kendini yakın gördüğg̈ kişilerle olan ilişkileri ifade etmektedir. Bu sosyal ilişkiler işletme içindeki kararları etkileyen kişiler arası ilişkiler ağıyla kendini göstermektedir (Eren, 2012). İşletme içerisindeki informal yapının farkına varılmadığı ve yönetilemediği durumlarda direncin kısa sürede üstesinden gelinmesi kolay olmayacaktır. Çünkü bu informal bağ bazen o kadar kuvvetli olabilmektedir ki çalışanlar bu bağı zedelememek için güçlü bir direnç içerisine girmektedirler. Bu konudaki ifadelerden biri durumu şöyle açıklamaktadır: 
...bizler genellikle ekip olarak birlikteyiz ve bir arkadaşımız çıkarılmak istediğinde buna karşı çıkıyoruz. Satın alma sonrasında şefimiz işten çıkarıldı ve biz buna karşı tepki gösterdik (Erkek, çalışan, 10 ylllık iş deneyimi, restoran işletmesi).

Diğer 2 çalışan ise duygularını şöyle dile getirmiştir:

...ilk değişim gerçekleştikten sonra gerçekten mutluyduk. Patronlar bize çok yakın davranıyordu ve her şeyin güzel olacă̆ını söylüyorlardı. Ancak gün geçtikçe hiç de söylenenler gibi olmadığı ve bazı arkadaşlarımızın işten çıkarıldıklarını gördük. Sevdiğimiz insanların işten çıkarıldığını görmek beni çok üzdü. Artık işletmeye sabahları gelirken ayaklarım geri geri gidiyordu Erkek, çalışan, 5 yıllık iş deneyimi, restoran işletmesi).

...bazı arkadaşlarımı işten çıkarıldı. 3 senedir beraber çalıştığımız ailece görüştüğüm kişiler vardı arasında. Aralarında yıllardır bu işi yapanlar var. O zamanlarda hepimize adil davranılmadı (Erkek, çalışan, 4 yıllık iş deneyimi, restoran işletmesi).

Görüşülen beş katılımcıdan üçünün değişimlerin işten çıkarılmaya neden olduğuna ve bu durumun işletme içerisinde yakın ilişki içerisinde yer alan çalışanlar arasında olumsuz duygulara neden olduğunu göstermektedir. Aynı zamanda, ortaya çıkan bu bulgular direnç gösterimlerinde sosyal ilişkilerin ve grup dinamiklerinin önemini ortaya koyan araştırmalarla (Hossan vd., 2013) uyumludur. Sonuç olarak çalışanların bu olumsuz duyguları bir pasif dirence işaret etmektedir. Bu süreçte yöneticilerin değişime direnç gösterimlerde onların duygusal ve sosyal ilişkilerini anlamaları ve yapacakları hamlelerde bu ilişkileri yönetmeleri gerekmektedir.

\section{SONUÇ}

Bu çalışma, değişime direnç sürecinde çalışan duygularının yönetilmesi gerekliliğini ortaya koymaktadır. Direnç, çalışanların işletme içerisinde gerçekleştirilmeye çalışılan değişime engel olma davranışını ifade etmektedir. Önceki çalışmalar direnci önlemede; tahmin etme, katılımı sağlama, iletişim, eğitim, uzlaşma ve zorlama gibi yöntemlerin kullanılmasını önermektedir (Akoğlan Kozak, 2004; Vos, 2006; Klarner vd., 2011). Ancak bu çalışmada duyguların yönetiminin de bu süreçte kullanılabileceği önerilmektedir.

Satın alma yoluyla önemli bir değişimin yaşandığı bir restoran örneği üzerinden yapılan çalışma sonucunda; çalışanların satın alma süreci ve sonrasındaki direnç göstermelerinin, kendilerine bağlı ve yönetici davranışlarından kaynaklanan nedenlerle ortaya çıtığını göstermektedir. Bu süreçte, çalışanların işlerini kaybetme, yeni işlere adapte olmama, yeni ekiple çalışamama gibi korkuları olduğu, çalışanların 
bu tür olumsuz duygular yanında, mutluluk gibi olumlu duygular da hissettiği ve bir duygusal karmaşa yaşadıkları gözlenmiştir. Burada birinci soru ile araştırma sonucunda çalışanların korku, stres ve üzüntü gibi olumsuz duyguları, mutluluk gibi olumlu duyguları yaşadıkları tespit edilmiştir. Ayrıca, değişim sürecinin başarılı olabilmesi için çalışanların duygularının farkında olunmasının önemli olduğuna yönelik ifadelere de bulunmaktadır.

Bu süreçte, yönetici ve sahiplerin çalışanlara empatik davranmadıkları ortaya çıkan önemli bir sonuçtur. Yöneticilerin çalışanlara empatik davranmadıklarında olumsuz duyguların işletme içerisinde arttığ 1 ve pasif direnişe yol açtığ çalışanlara sorulan ikinci soru ile ortaya çıkmıştır.

Araştırmanın üçüncü sorusuna verilen cevaplara göre çalışanların işletme içerisinde sosyal ilişkilere önem verdikleri tespit edilmiştir. Buna bağlı olarak çalışanların işletme içerisinde ve dışarısında birlikte vakit geçirdikleri, beraber çalışmaktan hoşlandıkları insanların işten çıkarılmasının bu çalışanları etkilediği ortaya çıkmıştır. $\mathrm{Bu}$ çalışanların birlikte olumsuz duygular içerisine girdikleri ve benzer duygusal tepkiler verdiği belirlenmiştir.

Bu çalışma sonucuna bakarak, değişime direncin önlenmesi veya minimum seviyede atlatılabilmesi için bu süreçte ve sonrasında duyguların yönetilmesinin önemli olduğu söylenebilir. Liu ve Perrewe (2005), değişim sürecinde çalışanların yoğun duygular yaşadığını belirtmektedirler. Yöneticiler çalışanların değişime gösterdikleri tepkileri azaltmak amaciyla daha fazla duygusal konulara eğilmelidirler. Nitekim önceki çalışmalar da değişim sonucunun çalışanların duygularını ve performansını etkilediğini ortaya koymaktadır (Günkel, 2015; Sinkovics vd., 2011; Oreg, 2006).

Son yıllarda restoran işletmelerinin sık sık el değiştirmesi, bu süreçte ağırlıklı olarak, finansal boyutla ilgilenilmesi, mimariye yatırımlar yapılması ve çalışanların gözardı edilmesi yapılan değişimlerin başarısız olmasına neden olmaktadır. İlgili literatürde her ne kadar değişim ve kullanılan teknikler üzerine yoğunluk gösterse de değişime karşı oluşan direnç gibi insani boyutun yeteri kadar önemsenmediği (Akoğlan Kozak ve Genç, 2014), bu amaçla yapılacak yeni nicel çalışmalara ihtiyaç duyulduğunu göstermektedir. Değişim sürecinde duyguların önemine ilişkin çalışmaların artmasıyla yaşanan krizlerin fırsata çevrileceğinin ipuçlarını toplaması bakımından sektör çalışanları için de önemli olacaktır.

$\mathrm{Bu}$ süreçte çalışan duygularının doğru yönetilmesi bireylerin duygusal olarak değişimi kabul etmesini kolaylaştıracak ve işletmede olumlu bir iklim oluşturularak çalışan direnci azaltılabilecektir. Yöneticiler bu dönemde çalışanlarla daha fazla 
empati kurmalı, iş dışında da onlarla vakit geçirmeli, onların istek ve gereksinimleri saptanarak çözüm yolu aramalıdırlar. Bir anlamda çalışanın önemli ve bu değişimin onların da yararına olduğunun hissettirilmesi gerekmektedir.

\section{KAYNAKÇA}

Akoğlan Kozak, M. ve Genç, V. (2014). Değişim Sürecinde Ortaya Çıkan Direnci Önlemede Duyguların Yönetiminin Önemi: Hizmet İşletmeleri Açısından Bakış, Optimum Ekonomi ve Yönetim Bilimleri Dergisi, 1(2): 81-92.

Akoğlan Kozak, M. (2004). Değişim Yönetimi Otel İşletme Müdürlerinin Değişim Yönetimi ile İlgili Algılamaları Üzerine Bir Araştırma. Ankara: Detay Yayıncılık.

Avey, J., Tara S.W.V. and Fred, L. (2008). Can Positive Employees Help Positive Organizational Change? Impact of Psychological Capital and Emotions on Relevant Attitude and Behaviors, The Journal of Applied Behavioral Science, 44(1): 48-70.

Barutçugil, İ. (2004). Organizasyonlarda Duyguların Yönetimi. İstanbul: Kariyer Yayincilik.

Birleşme ve Satın Alma İşlemleri Raporu (2016). EY Building a Better Working World http://www.ey.com/Publication/vwLUAssets/MA 2016 Raporu/\%24FILE/EY MA 2 016.pdf

Bovey, H.W. and Hede, A. (2001). Resistance to Organizational Change: The Role of Cognitive and Affective Processes, Leadership \& Organization Development Journal, 22(8): 372-382.

Boyatzis, R.E. (2009). Competencies as A Behavioral Approach to Emotional Intelligence, Journal of Management Development, 28(9):749-770. http://dx.doi.org/10.1108/02621710910987647

Burnes, B. and Philip, J. (2011). Success and Failure in Organizational Change: An Exploration of the Role of Values, Journal of Change Management, 11(2): 133-162.

Cartwright, S. and Cooper, C. L. (1990). The Impact of Mergers and Acquisitions On People at Work: Existing Research and Issues, British Journal of Management, 1(2): 6576.

Coch, L. and French, J. (1948). Overcoming Resistance to Change, Human Relations, 1: 512-532. 
Coghlan, D. (1993). A Person-centred Approach to Dealing with Resistance to Change, Leadership \& Organization Development Journal, 14(4):10-14, https://doi.org/10.1108/01437739310039433

DiFonzo, N., Bordia, P. and Rosnow, R.L. (1994). Reining in Rumors, Organizational Dynamics, 23(1), 47-62.

Elving, W.J.L. (2005). The Role of Communication in Organizational Change, Corporate Communications: An International Journal, 10(2): 129-138, https://doi.org/10.1108/13563280510596943

Eren, E. (2012). Örgütsel Davranış ve Yönetim Psikolojisi. İstanbul: Beta Yayınc1lı.

Erkuş, A. ve Günlü, E. (2008). Duygusal Zekânın Dönüşümcü Liderlik Üzerine Etkileri, Dokuz Eylül Üniversitesi, İsletme Fakültesi Dergisi, 9(2): 187-209.

Folger, R. and Skarlicki, D. P. (1999). Unfairness and Resistance to Change: Hardship as Mistreatment, Journal of Organizational Change Management, 12(1): 3550. https://doi.org/10.1108/09534819910255306

Fugate, M., Kinicki, A.J. and Scheck, C.L. (2002). Coping with an Organizational Merger Over Four Stages, Personnel Psychology, 55(4): 905-928.

Gunkel, M., Christopher, S., Rossteutscher, T. and Birgitta, W. (2015). The Human Aspect of Cross-Border Acquisition Outcomes: The Role of Management Practices, Employee Emotions, And National Culture, International Business Review, 24: 394-408.

Hossan, C., Dixon, C. and Brown, D. (2013). Impact of Group Dynamics on Eservice Implementation, Journal of Organizational Change Management, 26(5): 853-873. http://dx.doi.org/10.1108/JOCM-07-2012-0097

Huy, N.Q. (1998). Emotional Capability, Emotional Intelligence, and Radical Change. Academy of Management Review, Special Multilevel Issue.

Kiefer, T. (2002). Understanding the Emotional Experience of Organizational Change: Evidence from A Merger. Advances in Developing Human Resources, 4(1): 39-61.

Klarner, P., By, R.T. and Diefenbach, T. (2011). Employee Emotions During Organizational Change, Scandinavian Journal of Management, 27: 332-340.

Kusstatscher, V. and Cooper, C. (2005). Managing Emotions in Mergers and Acquisitions. Cheltenham, U.K.: Edward Elgar Publishing Ltd. 
Liu, Y. and Pamela, L.P. (2005). Another Look at the Role of Emotion in the Organizational Change: A Process Model, Human Resource Management Review, 15: 263-280.

Marks, M.L. (1988). The Merger Syndrome: The Human Side of Corporate Combinations, Journal of Buyouts \& Acquisitions, 18-23.

Marks, M.L. and Mirvis, P.H. (2011). A Framework for The Human Resources Role in Managing Culture in Mergers and Acquisitions, Human Resource Management, 50(6): 859-877.

Mossholder, K.W., Settoon, R.P., Armenakis, A.A. and Harris, S.G. (2000). Emotion During Organizational Transformations an Interactive Model of Survivor Reactions, Group \& Organization Management, 25(3): 220-243.

Oreg, S. (2006). Personality, Context, and Resistance to Organizational Change, European Journal of Work and Organizational Psychology, 15(1): 73-101, Doi: $10.1080 / 13594320500451247$

Pardo del Val, M. and Fuentes, C.M. (2003). Resistance to Change: A Literature Review and Empirical Study, Management Decision, 41(2): 148-155, Doi. 10.1108/00251740310457597

Piderit, S.K. (2000). Rethinking Resistance and Recognizing Ambivalence: A Multidimensional View of Attitudes Toward an Organizational Change, Academy of Management Review, 25(4): 783-794.

Sabuncuoğlu, Z. ve Tüz, M. (2005). Örgütsel Davranış. Bursa: Aktüel Yayıncılık.

Schein, H.E. (1999). Sense and Nonsense About Culture and Climate, (Ed. N. M. Ashkanasy; C. P. M. Wilderom; M. F. Peterson), Handbook of Organizational Culture \& Climate, Sage, Thousand Oaks.

Scott, C.D. and Jaffe, D.T. (1988), Survive and Thrive in Times of Change, Training and Development Journal, April, pp. 25-7.

Sinkovics, R.R., Zagelmeyer, S. and Kusstatscher, V. (2011). Between Merger and Syndrome: The Intermediary Role of Emotions in Four Cross-Border M \& As, International Business Review, 20(1): 27-47.

Ülgen, H. ve Mirze, S.M. (2010). İşletmelerde Stratejik Yönetim. İstanbul: Beta Yayıncılık. 
Vakola, M., Tsaousis, I. and Nikolaou, I. (2004). The Role of Emotional Intelligence and Personality Variables On Attitudes Toward Organizational Change, Journal of Managerial Psychology, 19: 88-110.

Vos, J. (2006). The Role of Personality and Emotions in Employee Resistance to Change. (Unpublished PhD Thesis), Erasmus University Faculty of the Social Sciences, Rotterdam. 